\title{
EXPERIMENTAL AND NUMERICAL STUDIES ON MECHANICAL BEHAVIORS OF BEECH WOOD UNDER COMPRESSIVE AND TENSILE STATES
}

\author{
Wengang Hu*, Bingrui Chen \\ Nanjing Forestry University \\ China \\ TianXing Zhang \\ WuYi University \\ China
}

(Received April 2020)

\begin{abstract}
Effect of loading type (compression and tension) on mechanical properties, including elastic constants, yield strength and ultimate strength of beech (Fagus orientalis) wood were studied based on experimental and numerical methods. The mechanical behaviors of beech wood in compressive and tensile states were simulated by finite element method (FEM) using mechanical parameters measured in an experiment. The results showed that the effect of loading types on mechanical properties of beech was statistically significant. The elastic moduli measured in tension were all bigger than those in compression, but the Poisson's ratios determined in compression were bigger than those in tension. In compressive state, the yield and ultimate strengths of beech in longitudinal grain orientation were all smaller than those measured in tensile state, while the yield and ultimate strengths of beech in radial and tangential directions were higher than those of longitudinal direction. The results of the FEM in compression and tension were all well consistent with those measured by experiments respectively, and the average errors were all within $13.69 \%$. As a result, the finite element models proposed in this study can predict the mechanical behaviors of wood in tensile and compressive states.
\end{abstract}

KEYWORDS: Beech, elastic modulus, compression, tension, loading type, FEM, Fagus orientalis.

\section{INTRODUCTION}

Beech (Fagus orientalis) wood is a main wood species naturally grown and commonly used in the forest products industry, especially in furniture industries in China. However, with the 
decrease of qualified forestry resources, the wood materials should be used more scientifically and efficiently in wood products like furniture. Finite element method (FEM) has been commonly used in lots of engineering fields by the virtue of developing technologies (Liu et al. 2018, Zhou et al. 2017, Zhou et al. 2018, Hu et al. 2019, Valachova and Skotnicova 2019). Mackerle (2005) reviewed more than 300 articles published from 1995 to 2004 on using FEM in wood products and wood constructions, and the results emphasized that mechanical properties of wood were vitally important to the application of FEM in wood products.

The mechanical properties of wood are commonly divided into three stages including elasticity, plasticity and fracture. It is complicated to analyze the mechanical properties of wood with FEM by regarding it as an anisotropic material. In order to make it adjust to computer modeling, it is usually regarded as an orthotropic material. In this case, the mechanical properties of wood can be determined in longitude, radial and tangential directions by small clear wood samples.

Many studies have been investigated on elastic constants of wood through using different testing methods, such as electric resistance strain gauges (Aira et al. 2014, Adyin and Adyin 2018, Hu and Guan 2017a), non-destructive method (Tomazello et al. 2008, Xu et al. 2020), and resonant beam technique (Gerhard et al. 2020). Keunecke et al. (2008) performed tensile tests on dog-bone-shaped yew specimens and determined the three Young's moduli and six Poisson's ratios using a universal testing machine and a digital image correlation technique. Ozyhar et al. (2013) studied the influence of moisture on the elastic characteristics of beech wood by means of ultrasonic waves. Sobotka et al. (2017), also Andor and Bellovics (2020) used two methods for measurement Young's modulus elasticity: static tensile test and three-point bend test to obtain statistical evaluation about influence of these testing methods on the final values of modulus of elasticity. Gonçalves et al. (2011) compared the elastic constants of wood determined by ultrasonic wave propagation and static compression testing, and the results showed the ultrasonic test for determining the Young's and shear moduli of wood was found to be simpler and less expensive than the static compression test, and the results were equally useful.

Elastic constant, yield and ultimate strengths are basic parameters used in FEM. If these parameters can be applied to simulating the mechanical behaviors of wood through using FEM, then mechanical properties of small wood block can be used to analyze the large structure of wood products by FEM. It will contribute to the design of wood products, and reduce costs of time and material. Tankut et al. (2014) gave a bibliographical review of the FEM applied in the analysis of furniture products construction with wood including wood as a furniture construction material and its mechanical properties. Kasal et al. (2016) studied the moment resistance, stiffness and numerical analysis of various sizes of round-end mortise and tenon joints with L-shaped and T-shaped specimens. Structure optimization design of modified wood mortise-and-tenon joint furniture using finite element method was studied by Chen and Wu (2018). Withdrawal resistance of mortise-and-tenon joint was studied by experiment and FEM based on the elastic constants measured using compressive method (Hu and Guan 2017b, Xi et al. 2020).

Previous studies confirmed that mechanical properties of wood were basic parameters needed in FEM, and FEM has been widely used in structure design of wood products and wood constructions. However, the mechanical parameters used in the FEM were usually measured in compression by regarding mechanical properties of wood measured in compression are the same with those in tension, which will decrease the accuracy of simulation based on FEM. The effect of loading type on elastic constants has rarely been studied. The aim of this paper is to study the influences of different loading types, i.e., compression and tension, on mechanical properties (elastic constants, yield strength and ultimate strength) of beech wood, and introduce how to use these parameters to simulate the wood mechanical behaviors based on FEM. 


\section{MATERIAL AND METHODS}

\section{Materials and equipment}

All specimens were made with beech (Fagus orientalis) wood bought from local commercial supplier (Nanjing, China). The density averaged $712 \mathrm{~kg} \cdot \mathrm{m}^{-3}$, and the moisture content of beech was conditioned to and held at $12.03 \%$ before and during tests. In addition, the temperature was controlled in $20 \pm 2^{\circ} \mathrm{C}$, and the relative humidity was $65 \pm 3 \%$ during the entire process of experiment. A $100 \mathrm{kN}$ universal testing machine AG-IC (SHIMADZU, Japan) was applied to carry out the experiment. A static data acquisition instrument TDS-530 (TML, Japan) was applied to determine the elastic constants with electrical resistance strain gauges.

\section{Specimen preparation}

The specimens applied to determine the mechanical properties of beech in three grain orientations (longitudinal, radial, and tangential) and two loading types (compression and tension) were machined according to the GB/T 1935 (CNS 2009), GB/T 1939 (CNS 2009), GB/T 1938 (CNS 2009), GB/T 14017 (CNS 2009), respectively. The dimensions of compressive specimens in three directions were all $20 \mathrm{~mm}$ wide $\times 20 \mathrm{~mm}$ thick $\times 30 \mathrm{~mm}$ high. The dimensions of tensile specimens in radial (R) and tangential (T) directions were $30 \mathrm{~mm}$ wide $\times 20 \mathrm{~mm}$ thick $\times$ $150 \mathrm{~mm}$ long, and in longitudinal (L) direction was $20 \mathrm{~mm}$ wide $\times 15 \mathrm{~mm}$ thick $\times 370 \mathrm{~mm}$ long.

\section{Testing methods}

Fig. 1 shows dimensions, grain orientations, and positions of strain gauges of samples used to evaluate the elastic moduli $\left(E_{L}, E_{R}, E_{T}\right)$, Poisson's ratios $\left(v_{L R}, v_{L T}, v_{R T}, v_{R L}, v_{T R}, v_{T L}\right)$, and moduli of rigidity $\left(G_{R T} G_{R T}\right.$ and $\left.G_{R T}\right)$ of beech wood. Specimens shown in Fig. 1a, b and c were applied to measure elastic moduli and Poison ratios of beech wood, and specimens presented in Figs. 1d,e,f were used to determine moduli of rigidity of beech. Ten measurements were repeated for each specimen type. In addition, compressive yield and ultimate strengths of beech wood were also determined by the same size specimens (Fig.1a,b,c) without sticking strain gauges. Fig. 2 shows dimensions and positions of strain gauges of specimens used to measure the mechanical properties of beech in tension. The specimens shown in Fig. 2a (front view) and Fig. $2 \mathrm{~b}$ (top view) were used to determine mechanical properties of beech perpendicular to grain in tensile state. The elastic constants $E_{R}, v_{R L}, E_{T}$ and $v_{T L}$ were obtained, when the axial direction of specimens were radial and tangential respectively. Fig. $2 \mathrm{c}$ and Fig. $2 \mathrm{~d}$ were front view and top view of specimens used to measure $E_{L}, v_{L R}$ and $v_{L T}$ with the wide direction of specimen in radial and tangential directions respectively. Each test was measured with ten replications. The moduli of rigidity in tensile state were not available in this study, since specimens used to determine them were not available. Fig. 3 shows the setups for measuring the elastic constants of beech in compression and tension.

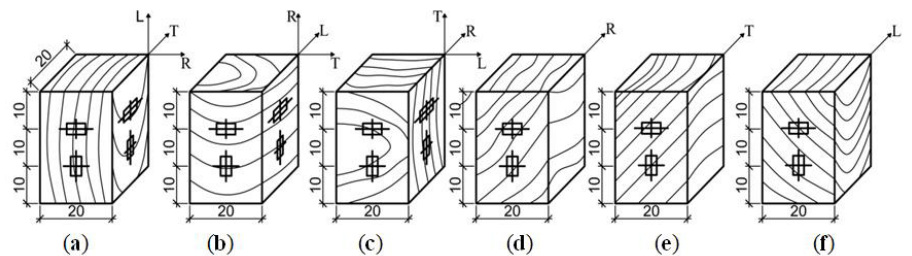

Fig. 1: Specimens used to determine elastic constants of beech in compression (units in $\mathrm{mm}$ ). 


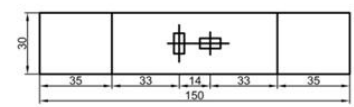

(a)

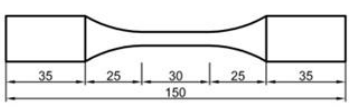

(b)

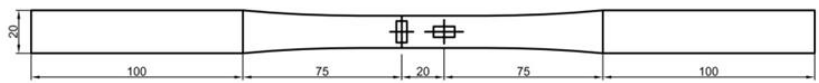

(c)

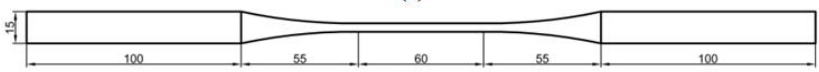

(d)

Fig. 2: Specimens used to measure the elastic constants of beech in tensile state (units in $\mathrm{mm}$ ).

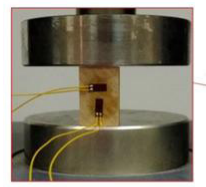

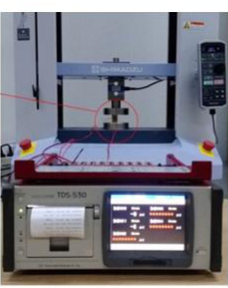

(a)

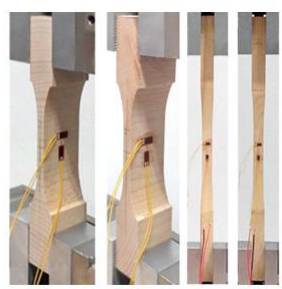

(b)

Fig. 3: Setup for measuring elastic constants of beech in compressive (a) and tensile, (b) states.

\section{Finite element model}

The finite element models were established by ABAQUS 6.14-1 software. Firstly, the geometric model of specimen was built in the same size with the beech wood specimen. It is recommended that established them in computer assistant design (CAD) software in advance and then imported them into ABAQUS.

The critical point to set up a finite element model was to specify the material properties of to model. The beech wood was regarded as an orthotropic material in this study. In the elastic stage of beech, the elastic constants were required to input as form of the elastic stiffness matrix shown in Eq. 1:

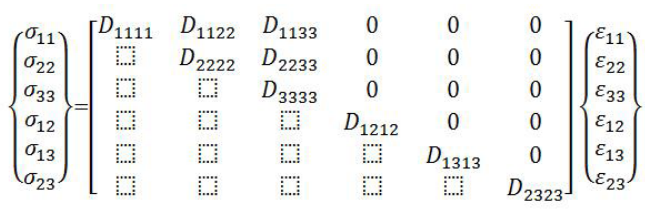

where: $D_{1111}=E_{L}\left(1-v_{R T} v_{T R}\right) \gamma$

$D_{2222}=E_{R}\left(1-v_{L T} v_{T L}\right) r$

$D_{3333}=E_{T}\left(1-v_{L R} v_{R L}\right) r$

$D_{1122}=E_{L}\left(v_{R L}+v_{T L} v_{R T}\right) \gamma$

$D_{1133}=E_{L}\left(v_{T L}+v_{R L} v_{T R}\right) \gamma$

$D_{2233}=E_{R}\left(\mathrm{v}_{R T}+\mathrm{v}_{L R} \mathrm{v}_{T L}\right) \gamma$

$D_{1212}=G_{L R}$

$D_{1313}=G_{L T}$

$D_{2323}=G_{R T}$

$\gamma=\frac{1}{1-\mathrm{v}_{L R} \mathrm{v}_{R L}-\mathrm{v}_{R T} \mathrm{v}_{T R}-\mathrm{v}_{L T} \mathrm{v}_{R L}-2 \mathrm{v}_{R L} \mathrm{v}_{T R} \mathrm{v}_{L T}}$ 
In plastic stage, the constitutive relationship of true stress and true strain are required. The true stress and true strain can be transported from engineering stress and strain by Eq. 2 and Eq. 3, respectively. In addition, the ultimate strength was regarded as the failure criterion of element. The elements will degrade when maximum stress exceeds the ultimate strength of wood.

$$
\begin{aligned}
\sigma_{i} & =\sigma_{\text {nom }}\left(1+\varepsilon_{\text {nom }}\right) \\
\varepsilon_{i} & =\ln \left(1+\varepsilon_{\text {nom }}\right)
\end{aligned}
$$

where: $\sigma_{i}$ - the true stress $(\mathrm{MPa}), \sigma_{n o m}$ - engineering stress $(\mathrm{MPa}), \varepsilon_{i}$ - the true strain, $\varepsilon_{\text {nom }}$ - engineering strain.

\section{RESULTS AND DISCUSSION}

\section{Mechanical properties of beech}

The elastic constants of beech in two loading types (compression and tension) were shown in Tab. 1. It suggests that the elastic moduli in tensile state were all bigger those in compressive state, while the Poison's ratios measured in tension were all smaller than those determined in compression. In addition, one-way analysis of variance (ANOVA) of the effect of the loading type on the elastic constants was conducted. The results showed the $p$-values of elastic moduli $\left(E_{L}\right.$, $E_{R}$ and $E_{T}$ ) were all smaller than 0.01 and $p$-values of Poisson's ratios were all bigger than 0.01 , which indicated that the effect of loading type on elastic moduli was statistically significant, but on Poisson's ratios were not.

Tab. 1: Comparisons of elastic constants of beech measured in tensile and compressive states.

\begin{tabular}{|l|c|c|c|c|c|c|c|c|c|c|c|c|}
\hline \multirow{2}{*}{$\begin{array}{c}\text { Loading } \\
\text { type }\end{array}$} & \multicolumn{3}{|c|}{$\begin{array}{c}\text { Elastic modulus } \\
\text { (MPa) }\end{array}$} & \multicolumn{4}{|c|}{ Poisson's ratio (dimensionless) } & \multicolumn{3}{c|}{$\begin{array}{c}\text { Shear modulus } \\
\text { (MPa) }\end{array}$} \\
\cline { 2 - 15 } & $E_{L}$ & $E_{R}$ & $E_{T}$ & $v_{L R}$ & $v_{L T}$ & $v_{R T}$ & $v_{R L}$ & $v_{T L}$ & $v_{T R}$ & $G_{L R}$ & $G_{L T}$ & $G_{R T}$ \\
\hline Compression & 12205 & 1858 & 774 & 0.500 & 0.710 & 0.530 & 0.078 & 0.038 & 0.370 & 899 & 595 & 195 \\
\hline Tension & 13644 & 2024 & 1051 & 0.410 & 0.460 & -- & 0.073 & 0.035 & -- & -- & -- & -- \\
\hline
\end{tabular}

Note: "--" suggested that these parameters were not measured or available.

The yield strength is usually used to differentiate the elasticity and plasticity of wood (Xu and Cai 2015), and the ultimate strength is applied to judge whether the wood is destroyed or not. Tab. 2 presents the yield and ultimate strengths of beech wood in three directions measured in compression and tension indicating that the yield strengths and ultimate strengths in compression were all smaller than those in tension in $\mathrm{L}$ direction, while the yield strengths measured in compression in $\mathrm{R}$ and $\mathrm{T}$ directions were bigger than those measured in tension. In addition, the yield strengths and ultimate strengths of beech in $\mathrm{L}$ direction were all bigger than those in $\mathrm{R}$ and $\mathrm{T}$ directions, which was confirmed by previous studies (Xu and Cai 2015, Franke and Quenneville 2013). The ANOVA of effect of loading types on yield strengths and ultimate strengths were also conducted with their $p$-values all smaller than 0.01 meaning the effect of loading types on yield strengths and ultimate strengths was statistically significant. 
Tab. 2: Yield and ultimate strengths of beech measured in compressive and tensile states.

\begin{tabular}{|l|c|c|c|c|c|c|}
\hline \multirow{3}{*}{ States } & \multicolumn{2}{|c|}{ Longitudinal (MPa) } & \multicolumn{2}{c|}{ Radial (MPa) } & \multicolumn{2}{c|}{ Tangential (MPa) } \\
\cline { 2 - 7 } & $\begin{array}{c}\text { Yield } \\
\text { strength }\end{array}$ & $\begin{array}{c}\text { Ultimate } \\
\text { strength }\end{array}$ & $\begin{array}{c}\text { Yield } \\
\text { strength }\end{array}$ & $\begin{array}{c}\text { Ultimate } \\
\text { strength }\end{array}$ & $\begin{array}{c}\text { Yield } \\
\text { strength }\end{array}$ & $\begin{array}{c}\text { Ultimate } \\
\text { strength }\end{array}$ \\
\hline Compression & $53.62(12.1)$ & $58.21(6.5)$ & $12.00(3.7)$ & $23.82(12.2)$ & $6.23(15.4)$ & $48.88(4.7)$ \\
\hline Tension & $75.53(5.8)$ & $168.25(8.6)$ & $5.45(6.1)$ & $17.13(5.4)$ & $4.10(5.9)$ & $9.71(6.3)$ \\
\hline
\end{tabular}

Note: The values in parentheses are coefficient of variances (COV).

The typical load-displacement curves in compression and tension were shown in Fig. 4. It suggested that failure behavior of beech in tension was similar to brittleness, while the mechanical behavior of beech in compression was not the same with that in tension, especially, in $\mathrm{R}$ and $\mathrm{T}$ directions. The load increased continuously after the plastic stage because the beech wood was compressed to denser than before, making it more solid. Therefore, in this study, the assumption was that the wood compressed within small deformation stage within $8 \mathrm{~mm}$ displacement.

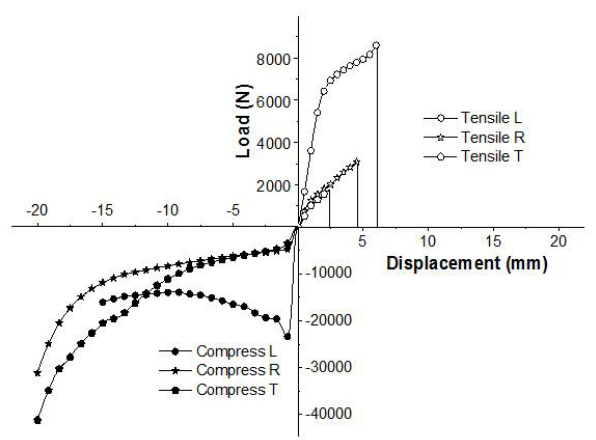

Fig. 4: Comparisons of mechanical behavior of beech measured in compressive and tensile states.

\section{Comparisons between FEM and experiment}

Fig. 5 shows the changes of stress distributions in longitudinal compression from beginning of loading (Fig. 5a) to the failure of sample (Fig. 5d). Figs. 5c,d were stress distributions during loading processes. The grain orientations of beech can be specified using local coordinates in ABAQUS. The load-displacement curves in three grain orientation were obtained by ABAQUS, which were used to compare with the results of experiments.

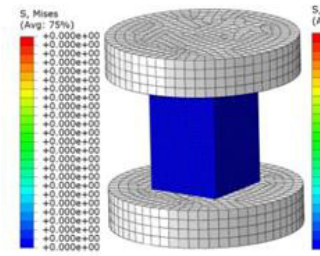

(a)

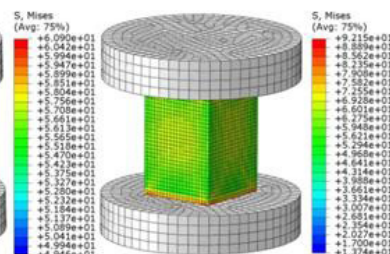

(b)

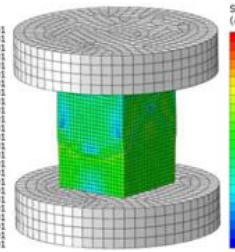

(c)

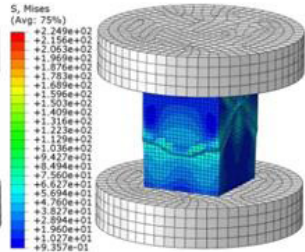

(d)

Fig. 5: Stress distributions of wood in compressive state based on FEM during loading process. 
Fig. 6 shows load-displacement curves of experiments and FEMs in three grain orientations in compressive state, suggesting that the results of FEMs were well consistent with those of experiments, especially in $\mathrm{R}$ and $\mathrm{T}$ grain orientations. Furthermore, Tab. 3 shows the errors between the results of FEM and experiment compared at five certain points of displacements from $1 \mathrm{~mm}$ to $8 \mathrm{~mm}$ with $1 \mathrm{~mm}$ increment in $\mathrm{R}$ and $\mathrm{T}$ direction, and $0.5 \mathrm{~mm}$ increment in $\mathrm{L}$ direction. The average errors are $13.69 \%, 4.93 \%$ and $3.96 \%$ in $\mathrm{L}, \mathrm{R}$ and $\mathrm{T}$ directions, respectively.

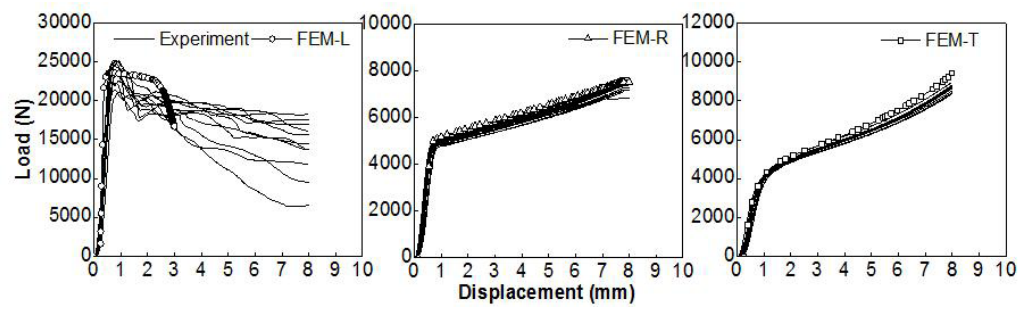

Fig. 6: Comparisons of load-displacement curves of experiment and FEM in compressive state.

Tab. 3: Comparisons of load values between FEM and experiment in compressive state at different displacement points.

\begin{tabular}{|c|c|c|c|c|c|c|c|c|c|}
\hline \multirow{2}{*}{$\begin{array}{c}\text { Displacement } \\
(\mathrm{mm})\end{array}$} & \multicolumn{2}{|c|}{ Longitudinal (N) } & \multirow{2}{*}{$\begin{array}{c}\text { Error } \\
(\%)\end{array}$} & \multicolumn{2}{|c|}{ Radial (N) } & \multirow{2}{*}{$\begin{array}{c}\text { Error } \\
(\%)\end{array}$} & \multicolumn{2}{|c|}{ Tangential (N) } & \multirow{2}{*}{$\begin{array}{c}\text { Error } \\
(\%)\end{array}$} \\
\hline & Observed & FEM & & Observed & FEM & & Observed & FEM & \\
\hline 0.5 & $\begin{array}{l}18362 \\
(14.1)\end{array}$ & 23245 & 28.23 & $4975(2.1)$ & 5183 & 4.18 & $4015(3.5)$ & 4332 & 7.90 \\
\hline 1.0 & $\begin{array}{c}23394 \\
(6.7)\end{array}$ & 23511 & 0.50 & $5281(2.3)$ & 5604 & 6.11 & 4965 (1.6) & 5196 & 4.67 \\
\hline 1.5 & $\begin{array}{c}20196 \\
(5.2)\end{array}$ & 23223 & 14.99 & $5592(2.3)$ & 5889 & 5.31 & $5484(1.7)$ & 5491 & 0.13 \\
\hline 2.0 & $\begin{array}{c}19570 \\
(5.5)\end{array}$ & 22890 & 16.96 & $\begin{array}{l}5908 \\
(2.2)\end{array}$ & 6199 & 4.93 & $5965(1.7)$ & 6199 & 3.92 \\
\hline 2.5 & $\begin{array}{c}19307 \\
(5.5)\end{array}$ & 21258 & 10.10 & $\begin{array}{l}6248 \\
(2.2)\end{array}$ & 6557 & 4.95 & $6483(1.7)$ & 6557 & 1.14 \\
\hline 3.0 & $\begin{array}{c}18834 \\
(7.5) \\
\end{array}$ & 16690 & 11.39 & $6619(2.3)$ & 6891 & 4.10 & $7076(1.8)$ & 7502 & 6.02 \\
\hline Average & -- & -- & 13.69 & -- & -- & 4.93 & -- & -- & 3.96 \\
\hline
\end{tabular}

Note: The values in parentheses are coefficient of variances (COV).

Fig. 7 shows the stress distributions of beech in tensile state. It presents the variations of stress distributions during loading processes (Figs. 7a-d). The load-displacement curves of three grain orientations were output by ABAQUS. 


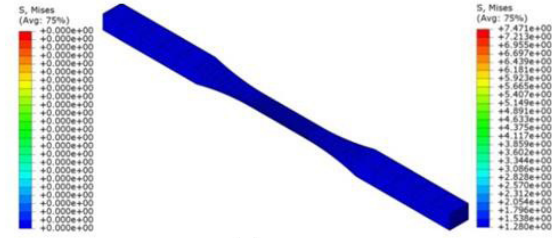

(a)

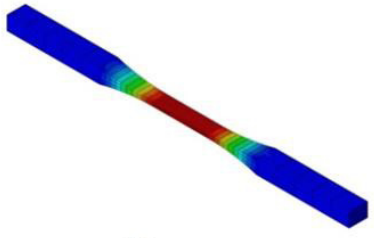

(b)

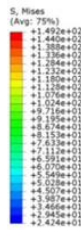

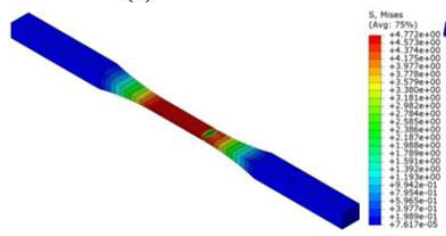

(c)

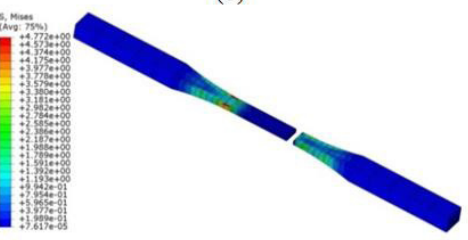

(d)

Fig. 7: Stress distributions of beech in tensile state during loading process.

Fig. 8 shows load-displacement curves of experiments and FEMs in tension, which suggests that load-displacement curves experienced the elastic, plastic and fracture stages. The results of the FEMs were in good agreement with those of experiments in three directions. In addition, errors between FEM and experiment in three directions were analyzed shown in Tab. 4 indicating that the average errors of FEMs in L, R, and T directions were 6.95\%, 2.44\%, and $10.92 \%$, respectively.
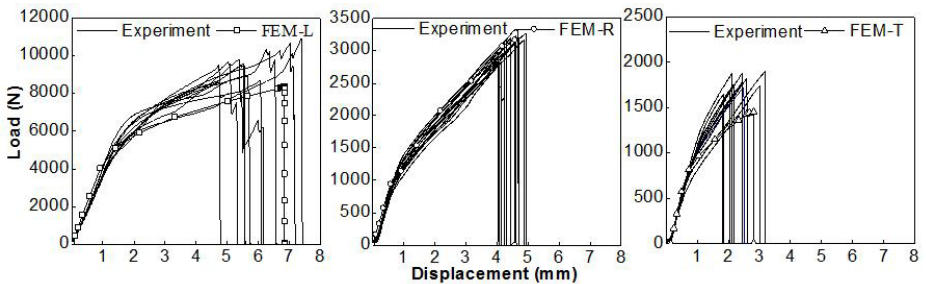

Fig. 8: Comparison of load-displacement curves between FEM and experiment in tensile state.

Tab. 4: Comparisons of load values between FEM and experiment in tensile state at different displacement points.

\begin{tabular}{|c|c|c|c|c|c|c|c|c|c|}
\hline \multirow{2}{*}{$\begin{array}{c}\text { Displacement } \\
(\mathrm{mm})\end{array}$} & \multicolumn{2}{|c|}{ Longitudinal (N) } & \multirow{2}{*}{$\begin{array}{c}\text { Error } \\
(\%)\end{array}$} & \multicolumn{2}{|c|}{ Radial (N) } & \multirow{2}{*}{$\begin{array}{c}\text { Error } \\
(\%)\end{array}$} & \multicolumn{2}{|c|}{ Tangential (N) } & \multirow{2}{*}{$\begin{array}{c}\text { Error } \\
(\%) \\
\end{array}$} \\
\hline & Observed & FEM & & Observed & FEM & & Observed & FEM & \\
\hline 1 & $3799(5.0)$ & 4022 & 5.86 & $1239(7.0)$ & 1256 & 1.32 & $499(4.4)$ & 572 & 14.68 \\
\hline 2 & $6207(5.6)$ & 5898 & 4.99 & $1829(5.6)$ & 1905 & 4.15 & $1010(8.3)$ & 970 & 3.88 \\
\hline 3 & $7294(4.9)$ & 6737 & 7.63 & $2342(4.6)$ & 2395 & 2.29 & $1307(9.7)$ & 1146 & 12.34 \\
\hline 4 & $8000(5.8)$ & 7256 & 9.30 & $2882(3.4)$ & 2939 & 1.99 & $1558(9.7)$ & 1359 & 12.79 \\
\hline Average & -- & -- & 6.95 & -- & -- & 2.44 & -- & -- & 10.92 \\
\hline
\end{tabular}

Note: The values in parentheses are coefficient of variances $(\mathrm{COV})$. 


\section{CONCLUSIONS}

In this study, the mechanical properties of beech wood in compression and tension were studied by experimental and numerical methods. Following conclusions were drawn: (1) The effect of loading type on elastic moduli were significant, but on Poisson's ratios were not. The elastic moduli measured in tensile state were all higher than those measured in compression, while the Poisson's ratios measured in compression were bigger than those in tension. (2) The results of ANOVA showed that the effect of loading types on yield and ultimate strengths were statistically significant. The yield and ultimate strengths of beech wood in L direction in compression were all smaller than those in tension. While the yield strengths of beech wood in $\mathrm{R}$ and $\mathrm{T}$ grain orientations in compression were bigger than those in tension. (3) The results of the proposed finite element model were all well consistent with those measured by experiments in compression and tension, and the errors were all within $13.69 \%$.

In conclusion, the finite element models created in this study were capable of predicting the mechanical behaviors of beech wood in compression and tension using the mechanical parameters measured in corresponding loading types. The methods used to obtain the mechanical properties should be considered when used in FEM. This study will contribute to promote FEM used in wood structures design and got more accurate simulations.

\section{ACKNOWLEDGMENTS}

This work was supported by a Scientific Research Foundation of Metasequoia teacher (163104060), Project from International Cooperation Joint Laboratory for Production, Education, Research and Application of Ecological Health Care on Home Furnishing.

\section{REFERENCES}

1. Aira., J.R., Arriaga., F., González, G.L., 2014: Determination of the elastic constants of scots pine (Pinus sylvestris L.) wood by means of compression tests. Biosystem Engineering 126: $12-22$.

2. Andor, K., Bellovics, B., 2020: Analysis of modulus of elasticity of spruce beams under bending with and without fibre reinforcement. Wood Research 65(1): 101-110.

3. Aydin, Y., Aydin, M., 2018: Comparison of temperature dependent Young's modulus of oriental beech (Fagus orientalis L.) that determined by ultrasonic wave propagation and compression test. Turkish Journal of Forestry 19(2): 185-191.

4. Chen, Y,S., Wu, Z.H., 2018: Study on structure optimization design of modified wood furniture tenon structure based on the finite element analysis of ANSYS. Journal of Intelligent \& Fuzzy Systems 34(2): 913-922.

5. CNS GB/T 1935, 2009: Method of testing in compressive strength parallel to grain of wood.

6. CNS GB/T 1939, 2009: Method of testing in compression perpendicular to grain of wood.

7. CNS GB/T 1938, 2009: Method of testing in tensile strength parallel to grain of wood.

8. CNS GB/T 14017, 2009: Method of testing in tensile strength perpendicular to grain of wood.

9. Divos, F., Tanaka, T., Nagao, H., Kato, H., 1998: Determination of shear modulus on construction size timber. Wood Science and Technology 32(6): 393-402. 
10. Franke, S., Quenneville, P., 2013: Compression behavior and material parameters of radiata pine at different orientations to the grain. Journal of Materials in Civil Engineering 25(10): 1514-1523.

11. Gerhard, S., Maierhofer, J., Loidli, D., Puchegger, S., Stanzl-Tschegg, S., 2020: Elastic constants of six wood species measured with the resonant beam technique. Wood Research 65(2): 347-352.

12. Goncalves, R., Trinca, A.J., Cerri, D.G.P., 2011: Comparison of elastic constants of wood determined by ultrasonic wave propagation and static compression testing. Wood and Fiber Science 43(1): 64-75.

13. Hu, W.G., Guan, H.Y., 2017a: Study on elastic constants of beech in different stress states. Journal of Forestry Engineering 2(06): 31-36.

14. Hu, W.G., Guan, H.Y., 2017b: Investigation on withdrawal capacity of mortise and tenon joint based on friction properties. Journal of Forestry Engineering 2(04): 158-162.

15. Hu, W.G., Wan, H., and Guan, H.Y., 2019: Size effect on the elastic mechanical properties of beech and its application in finite element analysis of wood structures. Forests 10(9): 783.

16. Keunecke, D., Hering, S., Niemz, P., 2008: Three-dimensional elastic behaviour of common yew and Norway spruce. Wood Science and Technology 42(8): 633-647.

17. Kasal, A., Smardzewski, J., Kuşkun, T., Erdil, Y.Z., 2016: Numerical analyses of various sizes of mortise and tenon furniture joints. BioResources 11(3): 6836-6853.

18. Liu, J.X., Zhou, W., Li, C., 2018: Stress wave vibration characterization of cross section of $\log$ using finite element method. Journal of Forestry Engineering 3(6): 19-24.

19. Mackerle, J., 2005: Finite element analyses in wood research: a bibliography. Wood Science and Technology 39(7): 579-600.

20. Ozyhar, T., Hering, S., Sanabria, S.J., Niemz, P., 2013: Determining moisture-dependent elastic characteristics of beech wood by means of ultrasonic waves. Wood Science and Technology 47(2): 329-341.

21. Sobotka, J., Solfronk, P., Korecek, D., Kolnerova, M., 2017: Influence of testing methods on the final values of the modulus of elasticity E. MM Science Journal (05): 1942-1946.

22. Tankut, N.D., Tankut, A.N., Zor, M., 2014: Finite Element Analysis of Wood Materials. Drvna Industrija 65(2): 159-171.

23. Tomazello, M., Brazolin, S., Chagas, M.P., Oliveira, J.T.S., Ballarin, A.W., Benjamin, C.A., 2008: Application of X-ray technique in nondestructive evaluation of eucalypt wood. Maderas-Ciencia y Tecnologia 10(2): 139-149.

24. Valachova, D., Skotnicova, I., 2019: Using the finite element method to predict heat dissipation in a timber frame building construction. Wood Research 64(5): 859-870.

25. Xi, X., Yang, Y., Zhang, Z.F., 2020: Pull-out force and finite element analysis of T-type components of Vitex negundo L. scrimber with different node forms. Journal of Forestry Engineering 5(1): 182-187.

26. Xu, B.H., Cai, J., 2015: State-of-the-art in strength criteria for wood. China Civil Engineering Journal 48(1): 64-73.

27. Xu, W., Fang, X.Y., Han, J.T., Wu, Z.H., Zhang, J.L., 2020: Effect of coating thickness on sound absorption property of four wood species commonly used for piano soundboards. Wood and Fiber Science 52(1): 28-43.

28. Zhao, Z., Sakai, S., Wu, D., Chen, Z., Zhu, N., Huang, C., Sun, S., Zhang, M., Umemura, K., Yong, Q. 2019: Further exploration of sucrose-citric acid adhesive: investigation of optimal hot-pressing conditions for plywood and curing behavior. Polymers 11:1996. 
29. Zhou, C.M., Yu, M.N., Zhou, T., 2018: Experimental study on three-dimensional shape mapping of complex furniture. EURASIP Journal on Image and Video Processing (9): 89.

30. Zhou, F.S., Li, L.J., Ouyang, Y.B., 2017: Lightweight research of mower frame based on ANSYS. Journal of Forestry Engineering 2(6): 103-109.

\author{
Wengang Hu*, Bingrui Chen \\ Nanjing Forestry University \\ Co-Innovation Center of Efficient Processing and Utilization of Forest \\ Resources \\ College of Furnishings and Industrial Design \\ NANJING 210037 \\ China \\ *Corresponding author: hwg@njfu.edu.cn
}

TianXing Z Zang

Wuyi University

School of Art and Design

JIANGMEN, 529020

China 
